\title{
ASSÉDIO MORAL INTERPESSOAL E ORGANIZACIONAL: ALCANCES E LIMITES DOS PROGRAMAS DE COMPLIANCE
}

\section{INTERPERSONAL AND ORGANIZATIONAL MORAL ASSESSMENT: SCOPE AND LIMITS OF COMPLIANCE PROGRAMS}

ERICK ALAN DE LIMA

Mestre em Direito Empresarial e Cidadania (Atividade empresarial e Constituição: inclusão e sustentabilidade) - UNICURITIBA.

\section{JOSÉ EDMILSON DE SOUZA LIMA}

Docente do Mestrado em Direito do Centro Universitário Curitiba (UNICURITIBA) e do Programa de Pós-Graduação em Meio Ambiente e Desenvolvimento (PPGMADE) da Universidade Federal do Paraná (UFPR).

\section{RESUMO}

A presente pesquisa tem como objetivo a verificação, inicialmente, das modalidades do assédio moral interpessoal, visualizando as suas principais modalidades, condutas que caracterizam o assédio e suas consequências no ambiente de trabalho e da própria empresa. O modo de gestão das empresas também faz parte desta investigação, verificando que ela possui grande influência no cotidiano laboral dos empregados, os efeitos danosos do modo de gestão empregado decorrem no momento em que os valores éticos são afastados, buscando-se apenas a produtividade e a lucratividade exacerbada, produzindo condutas nos trabalhadores que possibilitam a instauração do assédio moral organizacional. No ano de 2013, o Ministério Público do Trabalho recebeu cerca de três mil denúncias de assédio moral organizacional, sendo que trinta por cento 


\section{Personalidade Acadêmica Homenageada:}

Carlos Aurélio Mota de Souza (Universidade Ibirapuera - UNIB)

decorreram no setor bancário, segundo a FETEC-PR ${ }^{1}$, no ano de 2018 o assédio moral organizacional no setor bancário ainda persiste, concretizando-se, especialmente, através da instituição de metas a serem realizadas pelos empregados.

A partir de uma pesquisa bibliográfica e utilizando-se do método dedutivo, delimitar-se-ão os aspectos do assédio moral interpessoal e organizacional, tornando-se possível a análise dos alcances e limites dos programas de compliance que podem ser empreendidos nas empresas com o intuito de reduzir as práticas danosas ao meio ambiente laboral, frisa-se que estes programas utilizam-se da definição de regras éticas que nortearão o cotidiano da empresa, podendo impactar na diminuição das condutas assediantes.

A conclusão desta pesquisa decorreu das investigações iniciadas e debatidas no âmbito do grupo de pesquisa "Epistemologia e Direito", vinculado ao programa de Mestrado em Direito Empresarial e Cidadania do Centro Universitário Curitiba - UNICURITIBA.

O assédio moral é uma conduta que advém do início das relações laborais, estando, atualmente, difundida por todo o globo ${ }^{2}$, apesar de suas consequências aos trabalhadores, o assédio moral ainda perpetua-se e caracteriza-se como "[...] um conjunto de condutas abusivas e intencionais, reiteradas e prolongadas no tempo, que visam a exclusão de um empregado específico, ou de um grupo determinado destes, do meio ambiente de trabalho por meio do ataque à sua dignidade" ${ }^{3}$, prejudicando em razão "[...] de seu caráter multiofensivo, outros direitos fundamentais, a saber: o direito à integridade física e moral, o direito à intimidade, o direito ao tratamento não discriminatório, dentre outros." ${ }^{4}$.

\footnotetext{
${ }^{1}$ FETEC-PR. Assédio moral organizacional: novas estatísticas para um velho problema. 2018. Disponível em: <http://www.fetecpr.org.br/assedio-moral-organizacional-novas-estatisticas-para-umvelho-problema/>. Acesso em: 26 de jul. 2018.

2 BARRETO, Marco Aurélio A.. Assédio moral no trabalho - Responsabilidade do empregador: perguntas e respostas. 2. ed. São Paulo: LTr Editora Ltda., 2009. p.53

3 PAMPLONA FILHO, Rodolfo; BARROS, R. C. L. G.; WYZYKOWSKI, A.;. Assédio Moral Laboral e Direitos Fundamentais. 1. ed. São Paulo: LTr, 2014. p. 120.

${ }^{4}$ PAMPLONA FILHO, Rodolfo; BARROS, R. C. L. G.; WYZYKOWSKI, A.;. Assédio Moral Laboral e Direitos Fundamentais. 1. ed. São Paulo: LTr, 2014. p. 120.
} 


\section{Personalidade Acadêmica Homenageada:}

Carlos Aurélio Mota de Souza (Universidade Ibirapuera - UNIB)

Esta conduta pode ocorrer entre empregados que possuem o mesmo nível hierárquico, configurando o assédio moral interpessoal horizontal, evidencia-se que "São diversos os fatores determinantes desta forma de assédio, como as disputas por posições dentro da empresa, inveja, inimizade, transtornos mentais ou emocionais ou preconceito" 5 .

Sabe-se que o controle hierárquico permeia a grande maioria das relações de trabalho, estando os trabalhadores sujeitos às formas hierárquicas de controle de suas atuações, decorre desse controle uma das principais modalidades de assédio moral: o assédio moral vertical, que é "[...] praticado entre sujeitos de diferentes níveis hierárquicos, envolvidos em uma relação de subordinação."

$O$ assédio moral vertical possui sua modalidade descrita como descendente: "O assédio moral vertical descendente é o mais frequente. É o caso do empregador ou algum chefe superior hierárquico que faz pressão para a vítima cumprir metas muito rígidas ou metas impossíveis para a vítima." ${ }^{7}$, este ato violador é um abuso do poder diretivo, sendo que "Ao praticar o assédio moral, o empregador abusa do poder patronal que the é legalmente conferido, agredindo a personalidade e dignidade do trabalhador, mediante atitudes autoritárias, desumanas e vexatórias, prevalecendo-se de sua superioridade econômica." 8

Apesar da posição jurídica e econômica superior do empregador ou dos superiores hierárquicos nas empresas, isto não impede a ocorrência de assédio moral nomeado como vertical ascendente, em que há a prática de atos assediadores pelos subordinados em face de seus superiores hierárquicos ${ }^{9}$.

\footnotetext{
${ }^{5}$ CARVALHO, Augusto César Leite. Direito do Trabalho: Curso e Discurso. 2. Ed. São Paulo: LTr, 2018. p. 383.

${ }^{6}$ CATALDI, Maria José Giannella. Stress no meio ambiente de trabalho. 3. ed. São Paulo: LTr, 2015. p. 116.

7 TERCIOTI, Ana Carolina Godoy. Assédio moral no trabalho: danos causados ao trabalhador e medidas preventivas. 1 ed. São Paulo: LTr, 2013. p.35.

${ }^{8}$ XEREZ, Lena Marcílio. Tutela jurídica do empregado em face de assédio moral. São Paulo: LTr, 2015. p.23.

9 VILLATORE, Marco Antônio César; DINIZ, P. D. F. . O assédio moral, analisado sob uma perspectiva moderna, determinante medidas preventivas inovadoras. Revista Jurídica Unicuritiba, v. 2, $\quad$ p. 164-184, 2012. Disponível em: <http:// http://revista.unicuritiba.edu.br/index.php/RevJur/article/view/520/404>. Acesso em: 26 de jul. 2018.
} 


\title{
Personalidade Acadêmica Homenageada:
}

Carlos Aurélio Mota de Souza (Universidade Ibirapuera - UNIB)

A partir da análise das inúmeras modalidades de assédio moral interpessoal, tem-se que o assédio discrimina e estabelece diferenças entre empregados, deteriorando as liberdades individuais de um grupo ou pessoa.

Além do assédio moral interpessoal, há, também, a modalidade do assédio moral organizacional, a qual tem sido objeto de pesquisas recentes, sendo definido como:

\begin{abstract}
A prática do assédio moral organizacional deve estar relacionada com a atividade laboral ou atividade a ela correlata, como na hipótese do exercício do direito de greve, de atividade sindical, de atividade de cipeiro, entre outros. As atividades coletivas e de representação dos trabalhadores seguem em paralelo à atividade profissional na empresa, influenciando a sua organização e a forma de gestão do pessoal. Um dos pilares do capitalismo está assentado no controle do trabalho vivo a fim de obter o máximo crescimento em valores reais, portanto, é claro que a empresa tem interesse em moldar o trabalhador também nesse campo de atuação, nem que para isso possa vir a incorrer em condutas abusivas. Seu exercício não se restringe ao ambiente físico da empresa pois muitos são os relatos de trabalhadores em que a perseguição se estendeu para fora dos portões e do horário do trabalho. Como exemplo, há a situação emblemática do sindicalista francês espionado pela empresa quando se ausentava do local de trabalho para o desempenho das atividades sindicas. ${ }^{10}$
\end{abstract}

Para Aldacy Rachid Coutinho "O assédio moral organizacional é identificado como a opção pelo emprego da violência como política de gestão." ${ }^{11}$, assim, distorce-se os valores éticos para empregar um modelo de gestão que irá atingir produtividade e lucro em detrimento dos trabalhadores.

Os programas de compliance também podem ser elaborados visando conter as práticas supramencionadas, entretanto, a sua construção e aplicação devem conter uma abordagem sistêmica da empresa, tendo o enfoque nos setores ligados à gestão de pessoas que identificarão as práticas que não estarão em consonância com os parâmetros éticos da empresa. A real efetividade do programa de compliance dependerá do constante treinamento ético dos trabalhadores e da equipe de gestores, fazendo com que absorvam as diretrizes éticas da empresa e,

\footnotetext{
${ }^{10}$ ARAÚJO. Adriane Reis de. O assédio moral organizacional. São Paulo. LTr, 2012.

${ }^{11}$ COUTINHO, Aldacy Rachid. Meio Ambiente do Trabalho - a questão do poder empregatício e a violência silenciosa do perverso narcísico. Revista LTr, v. 77, n. 8, ago. 2013. p. 904.
} 


\section{Personalidade Acadêmica Homenageada:}

Carlos Aurélio Mota de Souza (Universidade Ibirapuera - UNIB)

consequentemente, atuando de modo respeitoso com os demais colegas de trabalho $^{12}$.

Sabendo-se dos danos ocasionados pelo assédio moral, os programas de compliance tornam-se uma opção de prevenção dessas condutas danosas, estabelecendo padrões éticos a serem observados nas empresas. Todavia, as ferramentas para efetivar esses padrões éticos ainda são insuficientes, sendo a principal a comunicação através da denúncia anônima, que, ainda assim, apresenta riscos ao denunciante. Esta pesquisa trouxe o suporte teórico sobre o assédio moral organizacional e interpessoal, juntamente com aspectos dos programas de compliance, assim possibilitará o desenvolvimento de nova pesquisa empírica que investigará a diminuição ou não do assédio moral nas empresas que utilizem-se de programas de compliance.

PALAVRAS-CHAVE: Indenizações; Gestão; Produtividade; Ética Empresarial.

\section{REFERÊNCIAS}

ARAÚJO. Adriane Reis de. O assédio moral organizacional. São Paulo. LTr, 2012.

BARRETO, Marco Aurélio A.. Assédio moral no trabalho - Responsabilidade do empregador: perguntas e respostas. 2. ed. São Paulo: LTr Editora Ltda., 2009. p.53

CARVAlHO, Augusto César Leite. Direito do Trabalho: Curso e Discurso. 2. Ed. São Paulo: LTr, 2018. p. 383.

CATALDI, Maria José Giannella. Stress no meio ambiente de trabalho. 3. ed. São Paulo: LTr, 2015.

COUTINHO, Aldacy Rachid. Meio Ambiente do Trabalho - a questão do poder empregatício e a violência silenciosa do perverso narcísico. Revista LTr, v. 77, n. 8, ago. 2013

\footnotetext{
${ }^{12}$ NASCIMENTO, Sônia Mascaro. Assédio Moral e Dano Moral no Trabalho. 3. Ed. São Paulo: LTr, 2015. p.88
} 
Personalidade Acadêmica Homenageada:

Carlos Aurélio Mota de Souza (Universidade Ibirapuera - UNIB)

FETEC-PR. Assédio moral organizacional: novas estatísticas para um velho problema. 2018. Disponível em: <http://www.fetecpr.org.br/assedio-moralorganizacional-novas-estatisticas-para-um-velho-problema/>. Acesso em: 26 de jul. 2018.

NASCIMENTO, Sônia Mascaro. Assédio Moral e Dano Moral no Trabalho. 3. Ed. São Paulo: LTr, 2015

PAMPLONA FILHO, Rodolfo; BARROS, R. C. L. G.; WYZYKOWSKI, A.; Assédio Moral Laboral e Direitos Fundamentais. 1. ed. São Paulo: LTr, 2014. p. 120.

TERCIOTI, Ana Carolina Godoy. Assédio moral no trabalho: danos causados ao trabalhador e medidas preventivas. 1 ed. São Paulo: LTr, 2013. p.35.

VILLATORE, Marco Antônio César; DINIZ, P. D. F. . O assédio moral, analisado sob uma perspectiva moderna, determinante medidas preventivas inovadoras. Revista Jurídica Unicuritiba, v. 2, p. 164-184, 2012. Disponível em: <http:// http://revista.unicuritiba.edu.br/index.php/RevJur/article/view/520/404>. Acesso em: 26 de jul. 2018.

XEREZ, Lena Marcílio. Tutela jurídica do empregado em face de assédio moral. São Paulo: LTr, 2015 